\title{
Fermentation of various soluble carbohydrates by rumen micro-organisms with particular reference to methane production
}

\author{
By J. W. CZERKAWSKI AND GRACE BRECKENRIDGE \\ Hannah Dairy Research Institute, Ayr \\ (Received 30 April 1969-Accepted 26 fune 1969)
}

\begin{abstract}
I. The fermentation of twenty-six different carbohydrates was studied in an artificial rumen.

2. The rates of fermentation varied widely, but except in the case of rhamnose the amount of methane produced was usually related to the amount of carbohydrate fermented $(6.0 \mathrm{cal} /$ roo cal of substrate). There was also a correlation between the amount of carbohydrate fermented and the amounts of steam-volatile acids formed.

3. Glucose, fructose and sucrose were fermented rapidly but mannitol, sorbitol, glucuronic and galacturonic acids, glucosamine, $D(-)$-arabinose, ribose, sorbose, trehalose and starch were fermented very slowly or not at all. $\mathrm{L}(+)$-Arabinose, xylose, galactose, mannose, cellobiose, maltose, lactose, raffinose, inulin, xylan and pectin were fermented at appreciable rates.

4 The methyl-pentose, rhamnose, was fermented but no methane was produced. Fucose was fermented very slowly.

5. The fermentation of sucrose and its constituent hexoses was characterized by a transient accumulation of lactate. The fermentation of rhamnose and of glucosamine was accompanied by a permanent accumulation of lactate. No measurable amounts of lactate were produced when any of the other sugars were fermented.
\end{abstract}

The inhibition of methane production by sheep given unsaturated fatty acids and related compounds has been extensively investigated (Czerkawski, Blaxter \& Wainman, 1966; Blaxter \& Czerkawski, 1966). It seemed that more rapid progress could be made in the investigation of these problems and of the mechanism of methanogenesis by experiments in vitro. Initially, a compromise technique was employed (Czerkawski, 1967) in which the mixed rumen micro-organisms were incubated in suitable containers inside the rumen. This gave some information about the mechanism of biohydrogenation of unsaturated fatty acids and about the amounts of these acids that could be tolerated by the micro-organisms. A serious disadvantage was the inability to measure changes in the production of rumen gases. With this in mind, an artificial rumen was built (Czerkawski \& Breckenridge, 1969). This apparatus can be used to investigate the fermentation of substrates, to study the effects of various compounds on methane production and on fermentation as a whole.

The most widely occurring sugars in plants are glucose, fructose, xylose, galactose and arabinose (Bailey, 1962). It has already been shown by Phillipson \& McAnally (1942) that structurally similar carbohydrates were often fermented by rumen microorganisms at different rates. Much of the subsequent published work has been concerned primarily with one aspect of fermentation, namely, the conversion of carbohydrates to steam-volatile acids (e.g. Elsden, 1945). The sugars most often used were sucrose, glucose and fructose, but the fermentation of pentoses was also investigated 
(McNaught, I95I; Heald, I952; Walker, I968). McNaught (195I) estimated methane production during fermentation of maltose, arabinose and xylose but did not exclude air during incubations and the methane values were generally low. As far as we know no systematic work has been carried out on the relation between the production of methane and the fermentation of various carbohydrates. The object of this work was to incubate each of several soluble carbohydrates with mixed rumen micro-organisms under specified conditions and to measure the changes in the concentrations of various products during incubation with particular reference to methane production.

\section{EXPER I MENTAL}

\section{Animals and diet}

Two wethers, fitted with rumen cannulas, were kept on a diet of $500 \mathrm{~g}$ molassed sugar-beet pulp given at $09.00 \mathrm{~h}$ and $500 \mathrm{~g}$ hay, together with $100 \mathrm{~g}$ barley, given at I $6.00 \mathrm{~h}$. Samples of rumen contents (about $300 \mathrm{ml}$ from each sheep) were withdrawn before the morning meal as described previously (Czerkawski \& Breckenridge, 1969). The samples were strained and pooled.

\section{The artificial rumen and its operation}

The procedure has been described fully by Czerkawski \& Breckenridge (I969). As a rule, each reaction vessel contained $200 \mathrm{ml}$ of artificial saliva (McDougall, 1948), $190 \mathrm{ml}$ water and $200 \mathrm{mg}$ ammonium carbonate. The inoculum of rumen contents (I00 $\mathrm{ml}$ ) was added after gassing both the buffer solution and the inoculum with $\mathrm{CO}_{2}-\mathrm{N}_{2}(5: 95, \mathrm{v} / \mathrm{v})$. After an interval of $\mathrm{I}_{5}-20 \mathrm{~min}$ to equilibrate the temperature the substrate ( $\mathrm{r} \cdot 5 \mathrm{~g}$ dissolved in $10 \mathrm{ml}$ water) was added to each vessel. Samples of reaction mixture and gas were taken for analysis as described previously.

\section{Analyses and materials}

Carbohydrates. Most of the carbohydrates used in these experiments were obtained from British Drug Houses Ltd, Poole, England. Sucrose was of the Analar grade. The following were Laboratory Reagent grade: $\mathrm{D}(+)$-xylose, glucose, $\mathrm{D}(-)$-fructose, galactose, maltose, lactose and glucosamine hydrochloride. The following were Biochemical Reagent grade: $\mathrm{L}(+)$-arabinose, $\mathrm{D}(-)$-arabinose, $\mathrm{D}(+)$-mannose, $\mathrm{L}(+)$ sorbose, cellobiose, trehalose $\left(2 \mathrm{H}_{2} \mathrm{O}\right)$, raffinose $\left({ }_{5} \mathrm{H}_{2} \mathrm{O}\right)$, inulin, mannitol, galacturonic and glucuronic acids, $\mathrm{L}(+)$-rhamnose and $\mathrm{L}(-)$-fucose. The sample of pectin (apple, $25^{\circ}$ grade) was also obtained from British Drug Houses Ltd. The sample of sorbitol was obtained from Koch-Light Ltd, Colnbrook, England. No attempt was made to check the purity of any of these compounds.

Gas analysis. The composition of gas was determined as described by Czerkawski \& Clapperton (1968).

Total steam-volatile acids (SVA) and lactate. The total concentration of SVA and the concentration of lactate were determined by the method of Conway (1962). The composition of SVA was determined in a limited number of experiments as described by Czerkawski (1967). 
Concentration of carbohydrates. The samples of reaction mixtures were centrifuged at $15000 \mathrm{~g}$ for $20 \mathrm{~min}$; the clear supernatant fluid was decanted and kept. The residues were washed once by centrifugation with diluted artificial saliva, 2 parts artificial saliva, 3 parts water, and were then extracted twice for 10 min with equal volumes of $5 \%$ trichloroacetic acid at $100^{\circ}$. The supernatant fluid and the pooled extracts were then diluted and the concentrations of carbohydrate were determined by the method of Smith (1956) to give a measure of the soluble sugar and the polysaccharide respectively.

The pentoses gave the largest extinction, ranging from 0.5 to 0.7 for solutions containing $40 \mu \mathrm{g} / \mathrm{ml}$. The hexoses, the methyl-pentoses, disaccharides and polysaccharides gave extinctions ranging from 0.3 to 0.5 with solutions containing $40 \mu \mathrm{g} / \mathrm{ml}$. The hexuronic acids and the sugar alcohols gave low extinctions varying from 0.03 to 0.30 at concentrations of $40 \mu \mathrm{g} / \mathrm{ml}$ but, since they were utilized very slowly by the rumen micro-organisms as judged by the small amounts of products, a very accurate estimation was not required. Glucosamine did not react at all with the phenol reagent and its concentration was determined by the method of Rondle \& Morgan (1955). The amounts of soluble carbohydrate that disappeared during fermentation were usually expressed as a percentage of the sugar added initially. It was assumed that the storage polysaccharide was a polyhexose and the results were calculated in terms of glucose, which gave an extinction similar to that given by starch.

In some experiments it was desirable to determine the concentration of two different sugars independently. When mixtures of sucrose and arabinose were incubated the optical density was determined at 492 and $480 \mu \mathrm{m}$, and the relative amounts of each sugar were calculated, using the specific extinction of each sugar.

\section{RESULTS}

\section{Results of some typical experiments}

The results of three separate experiments, in which various carbohydrates were incubated with rumen contents, are shown in Figs. I-3. Each experiment included a control vessel to which no substrate was added, a standard that contained sucrose and three vessels each with a substrate under investigation. Small amounts of hydrogen were formed during fermentation of most of the substrates used, but since the total amount of hydrogen formed was usually less than $2 \mathrm{ml} /$ vessel in all instances except $\mathrm{L}(+)$ arabinose, the results of hydrogen determination are not given here. With $\mathrm{L}(+)$ arabinose in three out of five experiments hydrogen began to accumulate towards the end of incubation. The rates of methane production (Fig. $\mathrm{I} a, b, c$ ) varied from substrate to substrate and they correlated largely, but not entirely, with the rate of production of SVA and the rate of utilization of substrate (Fig. $2 a, b, c$ ), defined as the amount of substrate that disappeared minus the amount of polysaccharide formed. Since the soluble carbohydrate content of the reaction mixture was usually small before the addition of substrates (less than I \% of the amount added) it was assumed that the carbohydrate added accounted for all the soluble carbohydrate. However, the initial amounts of polysaccharide were not negligible and tended to decrease with time in 

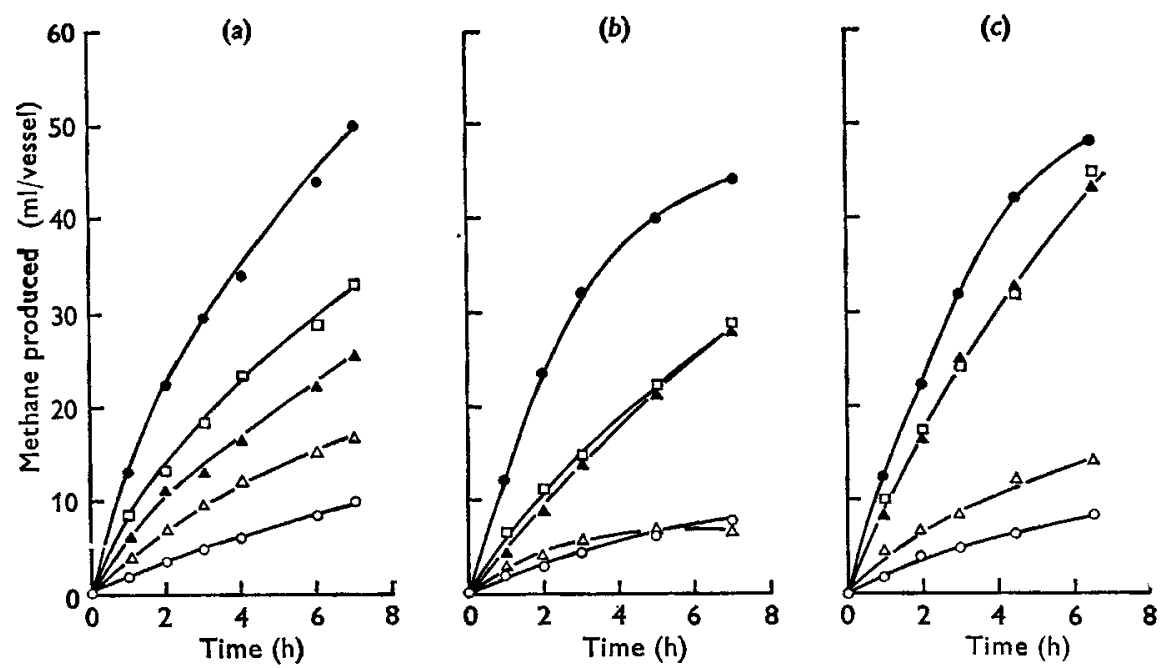

Fig. I. Amounts of methane produced when various carbohydrates were incubated with rumen contents. In each instance results of one experiment are given. (a) Sucrose (O), galactose $(\square)$, xylose $(\boldsymbol{\Delta})$, ribose $(\triangle)$, control-no substrate $(O)$; (b) sucrose $(\boldsymbol{O})$, mannose $(\square)$, lactose $(\Delta)$, rhamnose $(\Delta)$, control $(O) ;(c)$ sucrose $(\circlearrowleft)$, maltose $(\square)$, cellobiose $(\Delta)$, sorbose $(\triangle)$, control $(O)$.
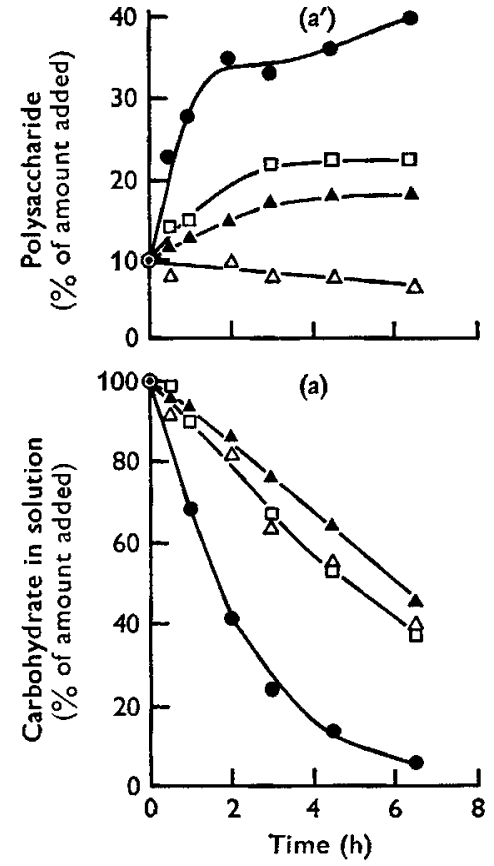

Fig. 2. Disappearance of substrate $(a, b, c)$ and the change in the amounts of polysaccharides $\left(a^{\prime}, b^{\prime}, c^{\prime}\right)$ with time, when various carbohydrates were incubated with rumen contents. The results are expressed as percentage of the weight of the carbohydrate added at the start of incubation. $\left(a, a^{\prime}\right)$ Sucrose $(\circlearrowleft)$, galactose $(\square)$, xylose $(\Delta)$, ribose $(\triangle) ;\left(b, b^{\prime}\right)$ sucrose $(\Theta)$, mannose $(\square)$, lactose $(\boldsymbol{\Delta})$, rhamnose $(\triangle) ;\left(c, c^{\prime}\right)$ sucrose $(\boldsymbol{O})$, maltose $(\square)$, cellobiose $(\boldsymbol{\Delta})$, sorbose $(\triangle)$. 
control experiments. The amounts of polysaccharide were expressed for convenience as percentage of the weight of the substrate added. The methane production was also correlated with total gas production (not given here). The behaviour of rhamnose was such that, although the substrate was utilized, the methane production was indistinguishable from the endogenous methane production. Although methane production was also strongly correlated with the production of SVA (except for rhamnose), the pattern of lactate production was characteristic of the type of sugar used (see Fig. 3).
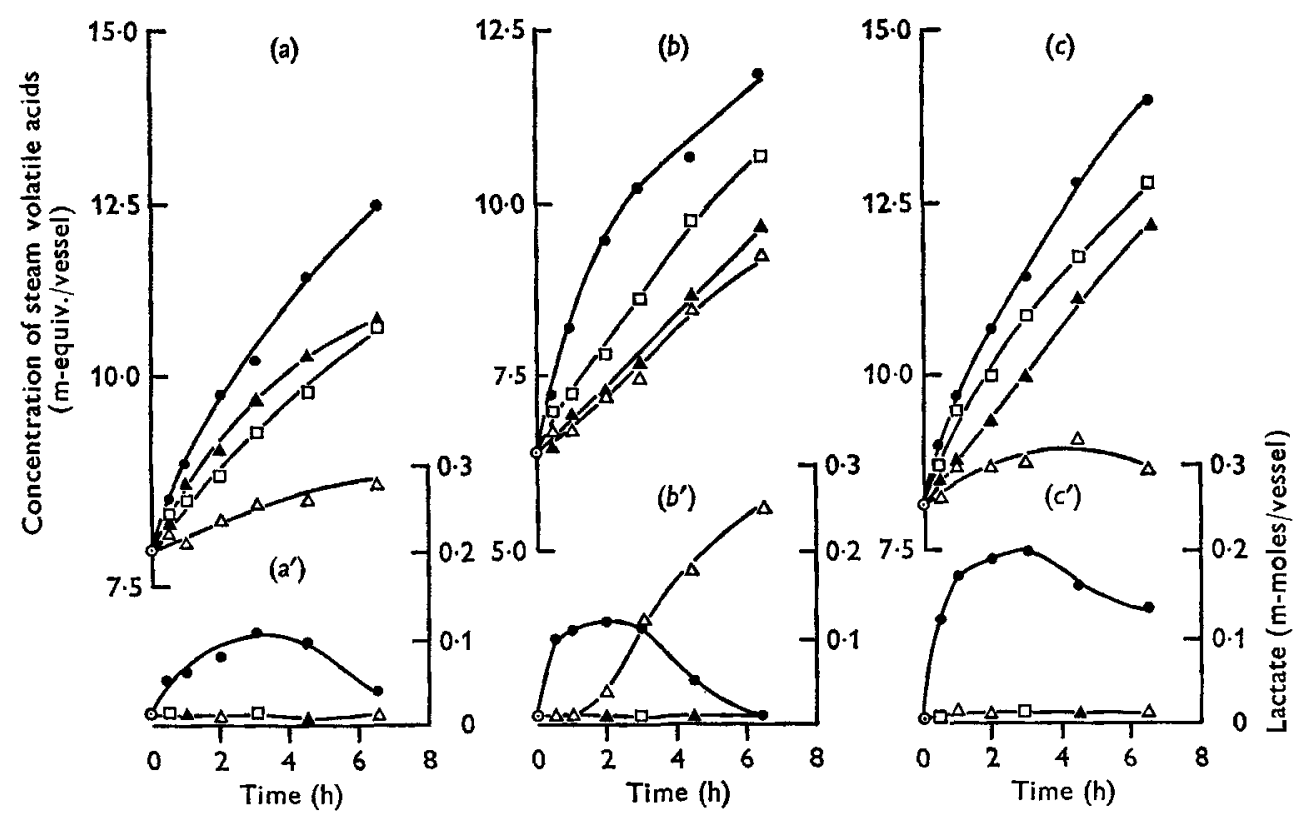

Fig. 3. Formation of steam volatile acids $(a, b, c)$ and lactate $\left(a^{\prime}, b^{\prime}, c^{\prime}\right)$ by rumen microorganisms during incubation with various substrates. $\left(a, a^{\prime}\right)$ Sucrose $(\bullet)$, galactose $(\square)$, xylose $(\boldsymbol{\Delta})$, ribose $(\Delta) ;\left(b, b^{\prime}\right)$ sucrose $(\bullet)$, mannose $(\square)$, lactose $(\Delta)$, rhamnose $(\Delta) ;\left(c, c^{\prime}\right)$ sucrose $(\bullet)$, maltose $(\square)$, cellobiose $(\Delta)$, sorbose $(\triangle)$.

The methane production was invariably greater with sucrose as substrate than with the other sugars tested. When glucose or fructose was incubated with rumen contents (see Table I) the amounts of methane produced were somewhat smaller than with sucrose. Stereochemical structure appeared to be important, but not always. For instance, the rates of methane production with galactose and mannose were similar, but both gave considerably less methane than did glucose. Ribose gave considerably less methane than xylose and, in agreement with the work of McNaught (195I) and Heald (1952), sorbose gave much less methane than fructose. The rates of utilization of cabohydrate were greatest with sucrose (Fig. 2). The fermentation of sucrose also resulted in the accumulation of the greatest amounts of microbial polysaccharides. The extent of this accumulation was directly correlated with the rate of fermentation in all the carbohydrates tested except ribose and rhamnose. It has been shown by Coleman (1968) that protozoa do not synthesize ribose from other sugars and that 
they take up ribose from solution, partly converting it into glucose. This might in part explain the apparent considerable disappearance of ribose and the lack of vigorous fermentation. Rhamnose was utilized almost as rapidly as xylose or galactose, and yet there was apparently no accumulation of microbial polysaccharides.

Sucrose (together with glucose and fructose) were the only sugars that led to a temporary accumulation of lactate. This accumulation of lactate is in agreement with the findings of Phillipson \& McAnally (1942) and, more recently, with the findings of Sutton (1968) and Walker (1968). The shapes of the curves suggest that at least for a time the rates of production of lactate were greater than the rates of its utilization, since the concentrations of lactate began to decrease when most of the substrate was exhausted. In any event the amounts of lactate produced were small $(0.1-0.2 \mathrm{~m}-$ moles/vessel) compared with the production of SVA $(5 \cdot 0-6 \cdot 0 \mathrm{~m}$-equiv./vessel). The steady accumulation of lactate or some substance reacting like lactate, when rhamnose was incubated with rumen microflora, cannot be explained at present.

\section{Summary of results of all the experiments}

The results of some of the relevant analyses from fifty-three experiments with twenty-six substrates are given in Table I. For convenience the substrates were segregated according to gross chemical structure, although this often bore little relation to the type and extent of fermentation. The fermentation characteristics of the following pairs of carbohydrates should be compared: $\mathrm{D}(-)$-arabinose and $\mathrm{L}(+)$ arabinose, sorbose and fructose, and cellobiose and trehalose. The results of the first two pairs are in agreement with the findings of McNaught (I95 I).

Since there was unavoidable variation in the concentration of the rumen contents taken from day to day there was much variability in replicate experiments (see results for sucrose in Figs. I-3). Nevertheless, it can be seen that there was a strong correlation between the rate of utilization of substrate and the rates of production of SVA and methane (except with rhamnose and ribose as substrate). The regression analyses of all the results showed that the fermentation of each mole of sugar (expressed as hexose) was probably associated with a mean production of $0.9 \mathrm{I}$ m-equiv. SVA and 0.22 moles of methane, the correlation coefficients being +0.85 and $+0.8 \mathrm{r}$ respectively. Since the mean ratio of methane produced to carbon dioxide produced was 0.21 , it can be readily calculated that the initial fermentation of $\mathrm{r} \cdot 0$ mole of hexose would result in the production of $\mathrm{I} \cdot \mathrm{O}$ mole of carbon dioxide.

The storage polysaccharides were formed rapidly at first; with most substrates, for every roo moles of sugar that disappeared from solution about 50 moles were converted into polysaccharides. Since the end-products of fermentation (SVA, $\mathrm{CO}_{2}, \mathrm{CH}_{4}$ ) during the initial hour accounted for just over $50 \%$ of the carbon of the substrate utilized, it follows that during the initial stages of fermentation virtually no carbon was used for synthesis of cell material other than storage polysaccharide. After $4.5 \mathrm{~h}$ of fermentation (Table 2), the end-products accounted for $40 \%$ of substrate utilized, and the rate of synthesis of storage polysaccharide decreased so that only $25 \%$ of the carbohydrate utilized was converted into storage material (cf. Walker, I968). Thus, allowing about $10 \%$ for incomplete recoveries in various estimations in agreement 
with Hungate (1966), 20-30\% of the carbon of the substrate might be used for synthesis of cell material other than storage polysaccharide.

The general characteristics of fermentation of the various sugars can be summarized by dividing them into four groups.

Table I. Rates of dissimilation of substrates, production of steam-volatile acids (SVA) and production of methane when various carbohydrates were incubated with rumen contents in vitro

\begin{tabular}{|c|c|c|c|c|}
\hline \multicolumn{5}{|c|}{ ors) } \\
\hline \multirow[b]{2}{*}{ Substrates } & \multirow[b]{2}{*}{$\begin{array}{l}\text { No. of } \\
\text { expts }\end{array}$} & \multicolumn{3}{|c|}{ Rate in Ist $h$} \\
\hline & & $\begin{array}{c}\text { Utilization } \\
\text { of substrate } \\
(\%)\end{array}$ & $\begin{array}{l}\text { Production } \\
\text { of SVA } \\
\text { (m-equiv.) }\end{array}$ & $\begin{array}{l}\text { Production } \\
\text { of } \mathrm{CH}_{4} \\
(\mathrm{ml})\end{array}$ \\
\hline $\begin{array}{l}\text { Pentoses } \\
\mathrm{L}(+) \text {-Arabinose } \\
\text { Xylose } \\
\text { Ribose } \\
\text { D(-)-Arabinose }\end{array}$ & $\begin{array}{l}4 \\
2 \\
I \\
I\end{array}$ & $\begin{array}{c}10 \cdot 6 \pm x \cdot 2 \\
8 \cdot 7 \pm x \cdot 4 \\
5 \cdot 2 \\
2 \cdot 8\end{array}$ & $\begin{array}{c}0.96 \pm 0.10 \\
I .02 \pm 0.10 \\
0.21 \\
0.02\end{array}$ & $\begin{array}{c}5 \cdot 0 \pm 1 \cdot 3 \\
3 \cdot 2 \pm 0 \cdot 4 \\
x \cdot 5 \\
0.6\end{array}$ \\
\hline $\begin{array}{l}\text { Hexoses } \\
\text { Glucose } \\
\text { Fructose } \\
\text { Mannose } \\
\text { Galactose } \\
\text { Sorbose }\end{array}$ & $\begin{array}{l}3 \\
3 \\
2 \\
2 \\
1\end{array}$ & $\begin{array}{l}23 \cdot 6 \pm 3 \cdot 0 \\
21 \cdot 3 \pm 4 \cdot 7 \\
13 \cdot 1 \pm 1 \cdot 5 \\
10 \cdot 1 \pm 2 \cdot 1 \\
0 \cdot 1\end{array}$ & $\begin{array}{l}1.54 \pm 0.06 \\
1.48 \pm 0.10 \\
0.76 \pm 0.04 \\
0.69 \pm 0.06 \\
0.18\end{array}$ & $\begin{array}{l}7 \cdot 4 \pm 0.8 \\
7.2 \pm 0.7 \\
5.1 \pm 0.4 \\
4.6 \pm 0.2 \\
0.7\end{array}$ \\
\hline $\begin{array}{l}\text { Disaccharides } \\
\text { Sucrose } \\
\text { Maltose } \\
\text { Cellobiose } \\
\text { Lactose } \\
\text { Trehalose }\end{array}$ & $\begin{array}{r}\text { I2 } \\
3 \\
2 \\
1 \\
1\end{array}$ & $\begin{array}{l}2 I \cdot 6 \pm I \cdot 0 \\
I I \cdot 9 \pm I \cdot I \\
I 0 \cdot 8 \pm I \cdot 8 \\
7 \cdot 4 \\
I \cdot 7\end{array}$ & $\begin{array}{c}I \cdot 52 \pm 0.10 \\
I \cdot 06 \pm 0.20 \\
0.50 \pm 0.12 \\
0.50 \\
0.16\end{array}$ & $\begin{array}{c}9 \cdot 1 \pm 0.7 \\
6 \cdot 5 \pm 2 \cdot x \\
6 \cdot 0 \pm 0 \cdot 7 \\
5 \cdot 1 \\
2 \cdot 4\end{array}$ \\
\hline $\begin{array}{c}\text { Trisaccharide } \\
\text { Raffinose }\end{array}$ & 2 & $7 \cdot 6 \pm 0.2$ & $0.91 \pm 0.06$ & $4 \cdot 8 \pm 0 \cdot I$ \\
\hline $\begin{array}{l}\text { Polysaccharides } \\
\text { Pectin } \\
\text { Inulin } \\
\text { Xylan } \\
\text { Starch }\end{array}$ & $\begin{array}{l}\text { I } \\
\text { I } \\
\text { I } \\
\text { I }\end{array}$ & $\begin{array}{l}-* \\
- \\
-\end{array}$ & $\begin{array}{l}1.50 \\
0.68 \\
0.96 \\
0.04\end{array}$ & $\begin{array}{l}3 \cdot 9 \\
4 \cdot 2 \\
1.4 \\
0.6\end{array}$ \\
\hline $\begin{array}{l}\text { Alcohols } \\
\text { Mannitol } \\
\text { Sorbitol }\end{array}$ & $\begin{array}{l}\mathbf{I} \\
\mathbf{I}\end{array}$ & $\begin{array}{l}3 \cdot 0 \\
2 \cdot 9\end{array}$ & $\begin{array}{l}0.02 \\
0.04\end{array}$ & $\begin{array}{l}0.7 \\
0.9\end{array}$ \\
\hline $\begin{array}{l}\text { Acids } \\
\text { Galacturonic } \\
\text { Glucuronic }\end{array}$ & $\begin{array}{l}\text { I } \\
\text { I }\end{array}$ & $\begin{array}{l}3 \cdot I \\
2 \cdot I\end{array}$ & $\begin{array}{l}0.30 \\
0.24\end{array}$ & $\begin{array}{l}0.8 \\
0.2\end{array}$ \\
\hline $\begin{array}{l}\text { Amine } \\
\text { Glucosamine }\end{array}$ & I & $I \cdot 5$ & 0.04 & 0.1 \\
\hline $\begin{array}{l}\text { Methylpentoses } \\
\text { Rhamnose } \\
\text { Fucose }\end{array}$ & $\begin{array}{l}3 \\
I\end{array}$ & $\begin{array}{c}7 \cdot 7 \pm 0.3 \\
I \cdot 2\end{array}$ & $\begin{array}{c}0.42 \pm 0.06 \\
0.06\end{array}$ & $\begin{array}{c}0.4 \pm 0.3 \\
0.2\end{array}$ \\
\hline
\end{tabular}

Group I. The carbohydrates placed in this group were poor substrates with o- $6 \%$ of added substrate fermented during the Ist hour. This group included the acid sugars (glucuronic and galacturonic acids), the alcohols (mannitol and sorbitol), two pentoses $(\mathrm{D}(-)$-arabinose and ribose), sorbose, trehalose and starch. 
Group 2. The substances placed in this group were attacked reasonably rapidly (6-16\% of added substrate/h). This group contained two pentoses $(\mathrm{L}(+)$-arabinose and xylose), two hexoses (galactose and mannose), three disaccharides (cellobiose, maltose and lactose), a trisaccharide (raffinose) and the polysaccharides inulin, xylan and pectin. However, pectin was fermented relatively slowly and it was difficult to decide whether to place it in group $\mathrm{I}$ or 2 . There was no accumulation of lactate when members of this group were fermented.

Table 2. Carbon balance (mg atom of $C$ ) after incubating various carbohydrates, each containing $50 \mathrm{mg}$ atoms of carbon, for $4.5 \mathrm{~h}$ with rumen contents

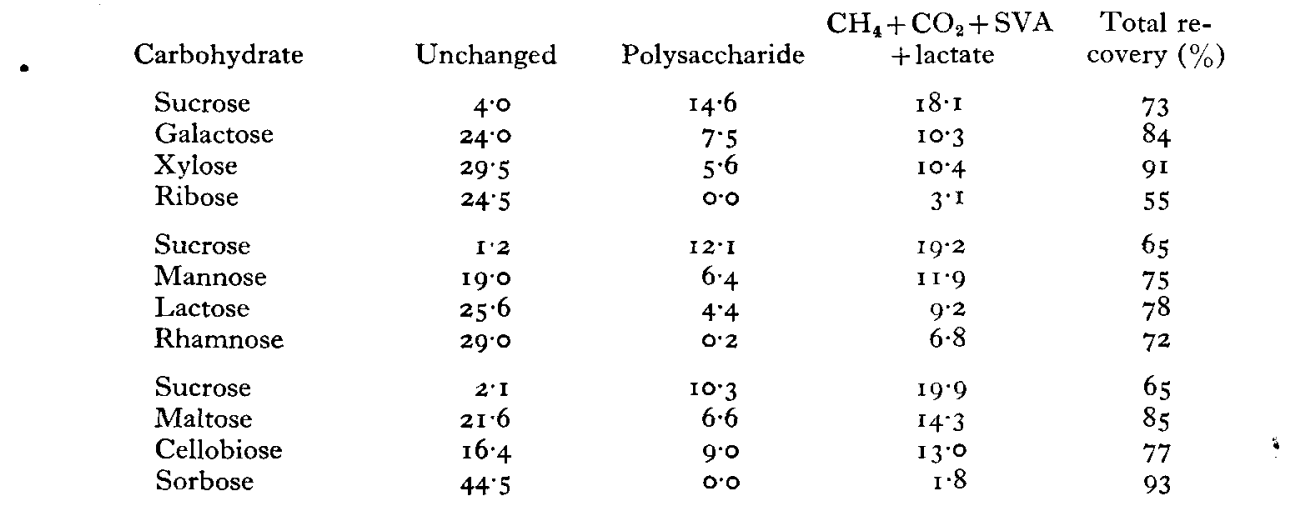

Table 3. Mean carbon recoveries during fermentation of various groups of carbohydrates (see p. 930). Carbohydrate containing $50 \mathrm{mg}$ atom of carbon was added to each vessel. The recovery values are sums of the amounts of unattacked sugar, the increases in the amounts of storage polysaccharides and in the end-products comprising $\mathrm{CH}_{4}, \mathrm{CO}_{2}, \mathrm{SVA}$ and lactate

\begin{tabular}{|c|c|c|c|}
\hline \multirow[b]{2}{*}{ Group } & \multirow[b]{2}{*}{$\begin{array}{l}\text { Substrate utilization } \\
\text { (range m-moles/h) }\end{array}$} & \multicolumn{2}{|c|}{ Recovery of carbon* ( $\mathrm{mg}$ atom/vessel) } \\
\hline & & I h & $4.5 \mathrm{~h}$ \\
\hline $\mathbf{I}$ & $0-0.5$ & $50.1 \pm 0.5$ & $45.9 \pm 0.9$ \\
\hline 2 & $0.5-1 \cdot 5$ & $51.8 \pm 0.7$ & $3^{6 \cdot 9 \pm \pm \cdot 6}$ \\
\hline 3 & $I \cdot 5-2 \cdot 5$ & $49 \cdot 3 \pm I \cdot 8$ & $30 \cdot 2 \pm I \cdot 4$ \\
\hline 4 & $0.5-1.0$ & $48 \cdot 8 \pm x \cdot 3$ & $35.9 \pm 0.4$ \\
\hline
\end{tabular}

* Mean values with their standard errors.

Group 3. The substances in this small group (glucose, fructose, sucrose) were excellent substrates ( $16-26 \%$ added substrate fermented $/ \mathrm{h}$ ). The fermentation of these substances was characterized by a rapid accumulation of lactate at the beginning of incubation and its subsequent decrease.

Group 4. Three substances were placed in this group-rhamnose, fucose and glucosamine. There was virtually no methane formed when these substances were fermented although relatively large amounts of rhamnose disappeared during incubation. In any event, the rates of fermentation of fucose and glucosamine were very slow. After $4 \mathrm{~h}$ the glucosamine began to be attacked fairly rapidly and this was accompanied by a 
steady production of lactate. There also appeared to be a small accumulation of lactate when fucose was fermented.

The mean recoveries of carbon within various groups of substrates after I and $4.5 \mathrm{~h}$ of incubation are summarized, together with the standard error in Table 3. After $4.5 \mathrm{~h}$ of incubation the recoveries of carbon varied from group to group and the magnitude of the deficit seemed to be directly related to the rate of fermentation, inasmuch as the recoveries of carbon were greatest in group I and least in group 3 .

\section{Composition of SVA}

The mean composition of SVA at the beginning of control experiments was: acetate $67.0 \%$, propionate $18.4 \%$, butyrate $1 \mathrm{I} \cdot 6 \%$, isovalerate $2 \cdot 2 \%$ and valerate $0.8 \%$, and there was usually no significant change during incubation. There was also no significant difference when substances in group $\mathrm{I}$ were incubated with rumen contents. The mean molar proportions of SVA at the end of incubation (4-7 h) of controls and of various carbohydrates are given in Table 4. The proportions of SVA obtained with glucose and fructose were similar to those with sucrose and they are not given in the table. In agreement with the findings of Sutton (1968), when sucrose was used there was usually a decrease in the proportion of acetate, an increase in the proportion of propionate and little change in the proportion of butyrate. The changes in the proportion of SVA with other substrates were less extensive and there was no definite pattern. The direction of some of these changes was often opposite to those that were described previously, e.g. butyrate from galactose and possibly sucrose (Sutton, 1968). This is not surprising since the proportions of various SVAs produced depend very much on the diet of the animals from which the rumen contents are taken.

\section{Table 4. Molar proportions of steam-volatile acids (\%) during incubation of carbohydrates with rumen contents}

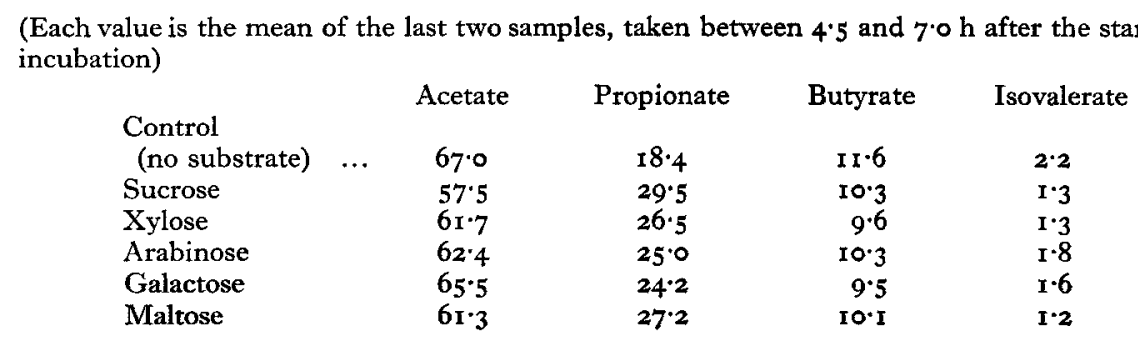

\section{Fermentation of mixtures of sugars}

Several mixtures of sugars were incubated with rumen contents. The mixtures studied in detail were those containing sucrose and arabinose, sucrose and maltose, arabinose and maltose, and mixtures of all three substrates. When no sucrose was present in the mixtures the results were largely additive, but when mixtures of sucrose and arabinose or maltose were incubated the results were not additive. In fact, both arabinose and maltose seemed to be fermented more efficiently in the presence of 
sucrose and, as a rule, the fermentation patterns of mixtures containing either arabinose or maltose with sucrose were similar to the pattern associated with sucrose.

The synergistic effect of sucrose is best illustrated by the results of an experiment in which various proportions of arabinose and sucrose were incubated with rumen contents. The rates of formation of methane and hydrogen are shown in Fig. 4. The synergistic effect of sucrose is illustrated in Fig. $4 a$, particularly in the mixture containing $\mathrm{I} \cdot 0 \mathrm{~g}$ arabinose and $0.5 \mathrm{~g}$ sucrose. The methane production was about $12 \%$ higher than would be expected if the contribution of arabinose had been in proportion to its amount in the mixture.

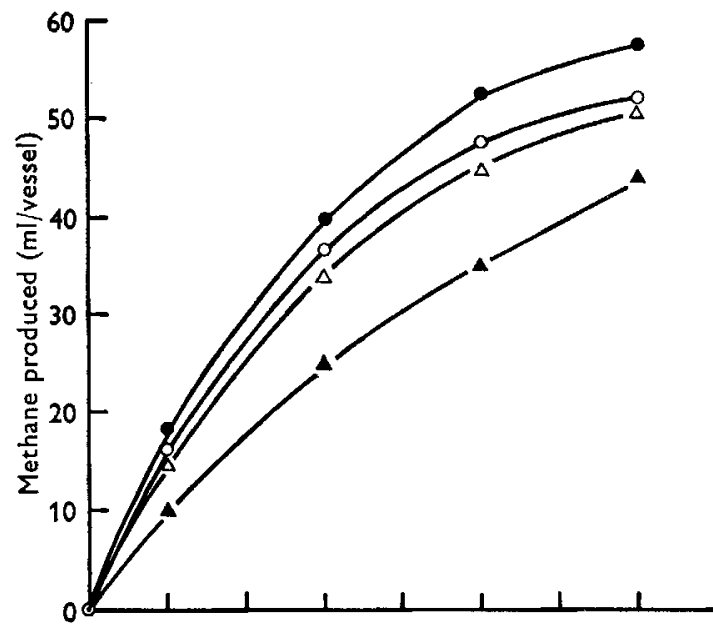

(a)

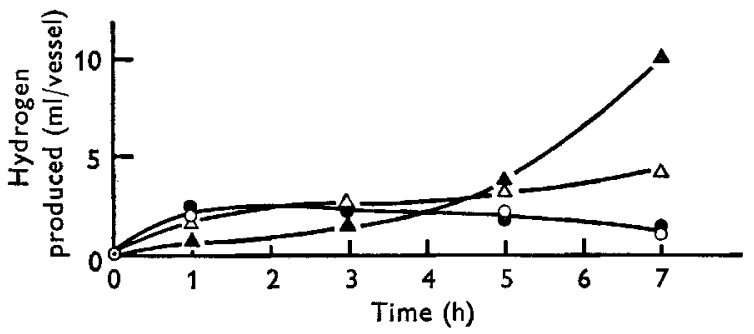

(b)

Fig. 4. Formation of methane and hydrogen during incubation of sucrose, arabinose and mixtures of these sugars with rumen contents. Sucrose I. $5 \mathrm{~g}(\odot)$; sucrose I.o g, arabinose $0.5 \mathrm{~g}(\bigcirc)$; sucrose $0.5 \mathrm{~g}$, arabinose $\mathrm{I} \cdot 0 \mathrm{~g}(\triangle)$; arabinose $\mathrm{l} .5 \mathrm{~g}(\mathbf{\Delta})$.

In this particular experiment the formation of hydrogen was somewhat greater than usually encountered and the results are shown in Fig. $4 b$. With sucrose only or with the mixture of sucrose and a small proportion of arabinose; the hydrogen formed tended to disappear as the fermentation progressed.

The rates of disappearance of the two sugars are shown in Fig. 5. The sucrose disappeared very rapidly no matter what proportion of arabinose was present. The rate of disappearance of arabinose was slower when a greater concentration of sucrose was present. The results of analyses of lactate in this experiment are shown in Fig. 6. 
Clearly the heights of the peaks of lactate concentrations and the time that elapsed before the accumulated lactate disappeared depended on the amount of sucrose initially present.

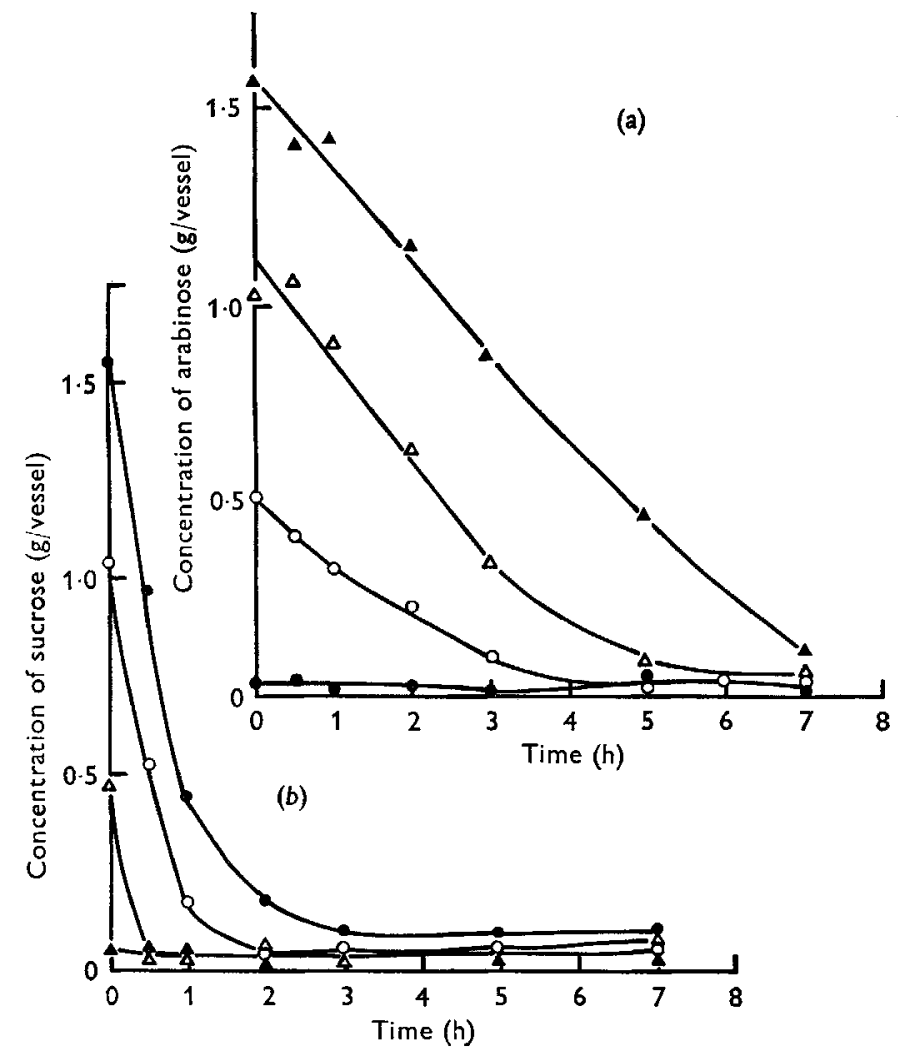

Fig. 5. Disappearance of sucrose and arabinose (inset) during incubation with rumen contents (symbols as in Fig. 4).

\section{DISCUSSION}

The results of fifty-three fermentation experiments using twenty-six different carbohydrates showed that, with the exception of rhamnose, the amount of methane produced was not very dependent on the type of carbohydrate, but rather was related to the amount of carbohydrate fermented. The mean amount of methane formed was 6.0 cal for $100 \mathrm{cal}$ of sugar fermented; this is in good agreement with results of measurement of methane production in vivo (see review by Czerkawski, 1969). The apparent non-specificity of methane production with respect to the type of carbohydrate fermented is consistent with the hypothesis that the carbohydrates are not direct precursors of methane and that the methanogenic bacteria do not utilize these substrates. The methanogens utilize some common product of fermentation of carbohydrates formed by the non-methanogenic micro-organisms.

The choice of a suitable substrate for routine screening of substances that might inhibit methane production is difficult. The largest amounts of methane were produced when the carbohydrates in group 3 were fermented (sucrose, glucose and 
fructose). These substrates were fermented rapidly and the methane production curves were not linear throughout the whole period of fermentation. When the initial amount of substrate was increased undesirable effects ensued, such as accumulation of large amounts of end-products, considerable drop in $\mathrm{pH}$ value and difficulties associated with measurement of large amounts of gas. The use of a smaller inoculum of rumen

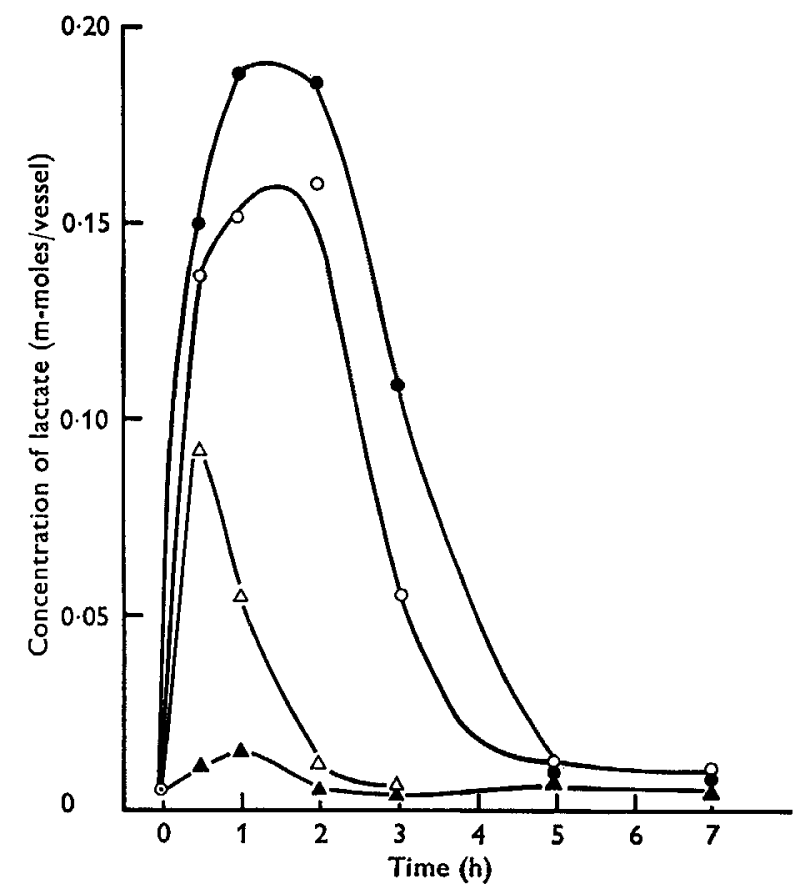

Fig. 6 Changes in the concentrations of lactate during incubation of sucrose, arabinose and mixtures of these substances with rumen contents (symbols as in Fig. 4).

contents was also inadvisable. Although the rate of fermentation during the first hour and in particular the rate of methane production were at first proportional to the size of the inoculum (Czerkawski \& Breckenridge, 1969), when the inoculum was small (less than $20 \%$ of the total volume) the fermentation characteristics altered after this time. Although the substrates were dissimilated at the predicted rates, the methane production usually fell to disproportionately small values or sometimes stopped altogether. This fall in methane production was accompanied by an ever-increasing rate of accumulation of hydrogen.

Clearly, the carbohydrates in group I were very poor substrates, but the possibility of adding small amounts of ribose to the energy-yielding substrates to facilitate the synthesis of nucleic acids should be considered.

It would seem that some of the more readily fermented sugars of group 2 (e.g. maltose, galactose, arabinose) would be suitable substrates, but it might be difficult to relate the results obtained with these substances to the results obtained in vivo. The composition of the carbohydrates in many foodstuffs is known reasonably well, and a synthetic mixture, with composition approximating to any given foodstuff could 
easily be prepared. However, the availability of the various components might not be the same as in the natural substrate. Thus, the sucrose in molassed sugar-beet pulp dissolves rapidly and is readily attacked by the micro-organisms. On the other hand, arabinose and xylose, the chief components of hemicellulose and other less soluble constituents of the diet, might not be readily available for fermentation. Arabinose and xylose are probably released slowly during rumen fermentation and are utilized as rapidly as they are released.

Bearing the above arguments in mind, some exploratory experiments were made (J. W. Czerkawski, unpublished results) in which solutions of several substrates were infused slowly at constant rates into the incubation vessels. The results were encouraging. Within certain limits the rates of fermentation were governed by the rate of infusion. Thus, within certain limits the rate of fermentation could be varied at will and kept constant. This is of great importance in inhibition studies where each vessel could serve as its own control. In further work we have drawn upon the information from the experiments reported here and are now making a systematic study of the inhibition of methanogenesis.

We are grateful to Mrs C. Faulds for her able supervision of various analytical techniques, and to Drs J. H. Moore and C. G. Harfoot for helpful discussions and encouragement.

\section{REFERENCES}

Bailey, R. W. (1962). Proc. N.Z. Soc. Anim. Prod. 22, 99.

Blaxter, K. L. \& Czerkawski, J. W. (1966). F. Sci. Fd Agric. 17, 417.

Coleman, G. S. (1968). \%. gen Microbiol. 54, 83 .

Conway, E. J. (1962). In Microdiffusion Analysis and Volumetric Error. London: Crosby, Lockwood \& Son.

Czerkawski, J. W. (1967), Br. F. Nutr. 21, 865.

Czerkawski, J. W. (1969). Wld Rev. Nutr. Diet. 11, 240.

Czerkawski, J. W., Blaxter, K. L. \& Wainman, F. W. (1966). Br. F. Nutr. 20, 349.

Czerkawski, J. W. \& Breckenridge, G. (1969). Br. F. Nutr. 23, 5 I.

Czerkawski, J. W. \& Clapperton, J. L. (I968). Lab. Pract. I7, 994.

Elsden, S. R. (1945). F. exp. Biol, 22, 5 r.

Heald, P. J. (1952). Biochem. F. 50, 503.

Hungate, R. E. (1966). The Rumen and its Microbes. New York: Academic Press Inc.

McDougall, E. I. (1948). Biochem. F. 43, 99.

McNaught, M. L. (I95I). Biochem. F. 49, 325.

Phillipson, A. T. \& McAnally, R. A. (1942). F. exp. Biol. 19, 199.

Rondle, C. J. M. \& Morgan, W. T. J. (1955). Biochem. F. 61, 586.

Smith, F. (1956). Meth. biochem. Anal. 3, i80.

Sutton, J. D. (1968). Br. Y. Nutr. 22, 689.

Walker, D. J. (1968). Appl. Microbiol. 16, 1672. 